\title{
Penerapan Metode VIKOR pada Pengambilan Keputusan Seleksi Calon Penerima Beasiswa Bidikmisi Universitas Terbuka
}

\author{
${ }^{1}$ Gede Suwardika, ${ }^{2}$ I Ketut Putu Suniantara \\ ${ }^{1}$ Statistika, Universitas Terbuka, ${ }^{2}$ Sistem Informasi, STMIK STIKOM BALI \\ ${ }^{1,2}$ Denpasar, Indonesia \\ E-mail: 1'isuwardika@ecampus.ut.ac.id, ${ }^{2}$ suniantara@stikom-bali.ac.id
}

\begin{abstract}
Abstrak-Proses seleksi penerimaan beasiswa bidikmisi melibatkan banyak persyaratan sebagai suatu kriteria, hal ini menjadi permasalahan tersendiri, sehingga memerlukan penyelesaian, sebagaimana pendukung keputusan dengan multikriteria. Salah satu konsep dasar pendukung keputusan dengan multikriteria adalah Metode VIKOR. Konsep dasar Metode VIKOR adalah menentukan ranking dari sampel-sampel yang ada dengan melihat hasil dari nilai utilitas, regrets dan jarak solution sebagai alternatif terbaik dari setiap sampel dengan pembobotan kriteria dari Metode Analysis Hierarchy Process. Penelitian ini bertujuan untuk menerapkan metode VIKOR pada penyeleksian penerima beasiswa bidikmisi yang dapat digunakan untuk membantu bagian kemahasiswaan dalam menentukan rekomendasi penerimaan beasiswa di Universitas Terbuka dengan mempertimbangkan berbagai kriteria yang telah ditentukan. Adapun kriteria yang digunakan dalam penelitian ini yaitu potensi akademik dan prestasi, kemampuan ekonomi, komitmen, urutan kualitas sekolah, representasi sekolah dan representasi asal daerah. Hasil penelitian menunjukkan bahwa Metode VIKOR dapat digunakan untuk membantu proses seleksi dan menentukan penerima beasiswa yang tepat. Pada Metode VIKOR masing - masing bobot yang diberikan menunjukkan hasil perengkingan yang sama, sehingga dapat dijadikan sebagai solusi kompromi dalam menangani permasalahan yang multikriteria.
\end{abstract}

Kata Kunci-Multikriteria, Beasiswa Bidikmisi, Metode VIKOR

Abstract-The selection process of bidikmisi scholarship involves many requirements as a criterion, thus requiring completion decisions supporters with multi-criteria. One of the decision support concept with multi-citeria is VIKOR Method. The basic concept of the VIKOR Method is to determine the rank of available samples by looking at the results of utility values, regrets and distance solutions as the best alternative of each sample by weighting criteria from the Analytic Hierarchy Process Method. This research purpose is to apply the VIKOR method in selecting the recipients of bidikmisi scholarship by considering various criteria that have been determined. The results shows that the VIKOR Method can be used to assist the selection process and determine the right scholarship recipients. At the VIKOR Method, each weight that are involved shows the result rank value, so it can be used as a compromise solution in dealing with multicriteria problems.

Keywords-multi-criteria, VIKOR Method, bidikmisi scholarship, decisions supporters 
INTENSIF, Vol.2 No.1 February 2018

ISSN: 2580-409X (Print) / 2549-6824 (Online)

http://ojs.unpkediri.ac.id/index.php/intensif

\section{PENDAHULUAN}

Lembaga pendidikan Universitas Terbuka menyediakan berbagai jenis beasiswa, mulai dari beasiswa berprestasi sampai beasiswa kurang mampu. Universitas Terbuka yang merupakan salah satu universitas negeri mengadakan program beasiswa bertujuan untuk meringankan beban mahasiswa dalam menempuh masa studi kuliah khususnya dalam masalah biaya. Terdapat beberapa program beasiswa, antara lain beasiswa PPA (Peningkatan Prestasi Akademik), beasiswa BBP (Bantuan Biaya Pendidikan) dan Bidik Misi serta beasiswa lainnya. Prosedur untuk memperoleh beasiswa tersebut terdapat beberapa syarat yang telah ditetapkan. Oleh karena itu, tidak semua pendaftar akan menerima beasiswa, hanya yang memenuhi syarat yang telah ditentukan yang dapat menerima beasiswa tersebut. Setiap proses seleksi penerimaan beasiswa, jumlah pendaftar beasiswa semakin bertambah dan para penyelenggara beasiswa tersebut harus melakukan penyeleksian terhadap mahasiswa yang layak mendapatkan beasiswa sehingga membutuhkan ketelitian dan waktu yang relatif lama untuk menentukan keputusan siapa yang berhak menerima beasiswa berdasarkan syarat yang telah ditentukan. Selain melibatkan jumlah pendaftar yang banyak, proses seleksi penerima beasiswa bidikmisi melibatkan banyak pertimbangan/syarat sebagai suatu kriteria. Karena banyaknya kriteria yang digunakan hal ini menjadi permasalahan tersendiri, sehingga memerlukan penyelesaian, sebagai pendukung keputusan dengan multikriteria.

Mempertimbangkan hal tersebut maka diperlukan suatu metode yang dapat menyeleksi pendaftar beasiswa dari masing-masing syarat yang telah ditentukan. Metode yang digunakan dalam pengambilan keputusan untuk seleksi penerimaan beasiswa adalah dengan menggunakan metode Multiple Criteria Decision Making (MCDM). MCDM melakukan pemilihan terbaik dari beberapa alternatif yang saling menguntungkan atas dasar beberapa syarat sebagai kriteria [1]. MCDM memiliki berbagai metode yang digunakan untuk menyelesaikan permasalahan yaitu Analysis Hierarchy Process (AHP) [2]. Penggunaan analisis AHP digunakan untuk mencari pembobotan kriteria yang digunakan pada metode VIKOR. Metode AHP memiliki kelebihan dalam penentuan bobot dan menjamin konsistensi saat menentukan bobot kriteria.

Metode VIKOR adalah metode perankingan dengan menggunakan indeks peringkat multikriteria berdasarkan ukuran tertentu dari kedekatan dengan solusi yang ideal. Konsep dasar VIKOR adalah menentukan ranking dari sampel-sampel yang ada dengan melihat hasil dari nilai-nilai utilitas dan regrets dari setiap sampel. Metode VIKOR telah digunakan oleh beberapa peneliti dalam MCDM, seperti dalam pemilihan vendor. Masalah MCDM dapat 
INTENSIF, Vol.2 No.1 February 2018

ISSN: 2580-409X (Print) / 2549-6824 (Online)

http://ojs.unpkediri.ac.id/index.php/intensif

direpresentasikan oleh matriks, dimana kolom menunjukan kriteria (atribut) dengan mempertimbangkan masalah yang diberikan dan baris menunjukkan alternatif [3] dan [4].

Metode VIKOR digunakan untuk mengatasi permasalahan multikriteria sistem yang kompleks yang berfokus pada ranking dan seleksi dari sebuah alternatif. Selain itu metode ini memiliki kelebihan dalam kompromi alternatif [5]. Prosedur yang diusulkan pertama menghitung solusi yang ideal dan negatif ideal setiap kriteria dengan mempertimbangkan kriteria dan bobot setiap alternatif, dan utilitas yang sesuai dan ukuran sesalan (regret) untuk setiap alternatif yang telah ditentukan [6]. Penelitian ini bertujuan untuk menyelesaikan permasalahan pemilihan calon penerima beasiswa bidikmisi dengan Metode VIKOR dalam penyeleksian penerimaan beasiswa di Universitas Terbuka?. Hasil analisis Metode VIKOR, diharapkan dapat digunakan sebagai pendukung keputusan bagi bagian kemahasiswaan dalam menentukan calon penerima beasiswa.

\section{METODE PENELITIAN}

Data yang digunakan dalam penelitian ini adalah data primer dan sekunder yaitu data pelamar/ pendaftar beasiswa bidikmisi mahasiswa Universitas Terbuka tahun 2017 sebanyak 55 mahasiswa dari dua kabupaten sebagai calon penerima beasiswa yang nantinya dijadikan alternatif. Sedangkan potensi akademik dan prestasi (C1), kemampuan ekonomi (C2), komitmen (C3), urutan kualitas sekolah (C4), representasi sekolah (C5) dan representasi asal daerah (C6) dijadikan sebagai kriteria. Adapun langkah-langkah untuk mencapai tujuan penelitian tersebut sebagai berikut:

1. Menentukan bobot kriteria dengan Metode AHP, dengan langkah - langkah sebagai berikut:

a. Membuat matriks perbandingan berpasangan dari setiap kriteria

b. Normalisasi matriks berpasangan

c. Menghitung prioritas relatif dari setiap kriteria

d. Mengukur konsistensi setiap kriteria

e. Menghitung nilai consisteny index (CI)

f. Menghitung cinsistency ratio $(\mathrm{CR})$

g. Memeriksa konsistensi penentuan bobot, bila CR kurang dari atau sama dengan 0,1 maka penentuan bobot konsisten, tetapi bila CR lebih besar dari 0,1 maka penentuan bobot kriteria harus diulang kembali.

2. Menerapakan metode VIKOR untuk meyelesaikan penyeleksian calon penerima biasiswa bidik misi, dengan prosedur sebagai berikut [7]: 
INTENSIF, Vol.2 No.1 February 2018 ISSN: 2580-409X (Print) / 2549-6824 (Online) http://ojs.unpkediri.ac.id/index.php/intensif

a. Membuat matriks keputusan dari alternatif dengan ukuran $X_{n \times c}$, dengan rumus sebagai berikut

$$
X=\begin{gathered}
C_{1} \\
A_{1} \\
A_{2} \\
A_{3} \\
\vdots \\
A_{n}
\end{gathered}\left[\begin{array}{ccccc}
x_{11} & x_{12} & x_{13} & \ldots & x_{1 n} \\
x_{21} & x_{22} & x_{23} & \ldots & x_{2 c} \\
x_{31} & x_{32} & x_{33} & \ldots & x_{3 c} \\
\vdots & \vdots & \vdots & \ddots & \vdots \\
x_{n 1} & x_{n 2} & x_{n 3} & \ldots & x_{n c}
\end{array}\right]
$$

Dimana $A_{i}$ alternatif ke-i, $i=1,2, \ldots, n ; C_{j}$ merupakan kriteria ke-j dan $x_{i j}$ adalah elemen dari matriks yang menunjukan tingkatan kinerja dari alternatif ke-i.

b. Menghitng nilai positif dan negatif sebagai solusi ideal, dengan rumus

$$
\begin{aligned}
f_{j}^{*} & =\left\{\min f_{i j} \mid j=1,2, \ldots, c\right\} \\
& =\left\{f_{1}^{*}, f_{2}^{*}, \ldots, f_{j}^{*}, \ldots, f_{c}^{*}\right\} \\
f_{j}^{-} & =\left\{\max f_{i j} \mid j=1,2, \ldots, c\right\} \\
& =\left\{f_{1}^{-}, f_{2}^{-}, \ldots, f_{j}^{-}, \ldots, f_{c}^{-}\right\}
\end{aligned}
$$

c. Melakukan normalisasi untuk menghasilkan matriks decision yang baru dari data pelamar beasiswa dengan ukuran $N_{n \times c}$, dengan rumus

$$
N_{i j}=\frac{f_{i i}^{*}-X_{i j}}{f_{i j}^{*}-f_{i j}^{-}}
$$

d. Menghitung matriks normalisasi dengan bobot, dengan rumus

$$
F_{i j}=N_{i j} \times B K_{i}
$$

$B K_{\mathrm{i}}$ merupakan bobot yang dihitung dengan menggunakan $A H P$ dengan banyaknya perhitungan $F_{n \times c}$.

e. Menghitung utility measure, dengan rumus

$$
\begin{aligned}
S_{i} & =\sum_{j=1}^{6} F_{i j} \\
R_{i} & =\max \left(F_{i 1}, F_{i 2}, \ldots, F_{i 6}\right) \\
S^{-} & =\max \left(S_{1}, S_{2}, S_{3}, \cdots, S_{55}\right) \\
S^{*} & =\min \left(S_{1}, S_{2}, S_{3}, \cdots, S_{55}\right) \\
R^{-} & =\max \left(R_{1}, R_{2}, R_{3}, \cdots, R_{55}\right) \\
R^{*} & =\min \left(R_{1}, R_{2}, R_{3}, \cdots, R_{55}\right)
\end{aligned}
$$

f. Menghitung indeks VIKOR (Q), dengan rumus sebagai berikut: 
INTENSIF, Vol.2 No.1 February 2018

ISSN: 2580-409X (Print) / 2549-6824 (Online)

http://ojs.unpkediri.ac.id/index.php/intensif

$$
Q_{1}=\left[v \frac{\left(S_{1}-S^{*}\right)}{\left(S^{-}-S^{*}\right)}\right]+\left[(1-v) \frac{\left(R_{1}-R^{*}\right)}{\left(R^{-}-R^{*}\right)}\right]
$$

dimana $v$ adalah bobot maksimum group utility yang biasanya itu diatur ke 0,5 .

g. Merengking alternatif dari Nilai VIKOR

Nilai indeks VIKOR diperoleh pada langkah yang direngking untuk menentukan pilihan alternatif terbaik yang ditentukan pada nilai VIKOR kecil yang menunjukkan kualitas yang lebih baik.

h. Melakukan solusi kompromi dengan dua solusi dengan selisih antara indeks VIKOR pertama dengan kedua atau kondisi Acceptable advantage.

\section{HASIL DAN PEMBAHASAN}

Sesuai dengan teknik analisis, langkah pertama yang dilakukan adalah menentukan prioritas bobot relatif (BK) kriteria dengan metode AHP yang terdiri dari 55 alternatif dan 6 ktiteri. Hasil perhitungan metode AHP diperoleh bobot kriteria sebagai berikut:

a. Penentuan bobot kriteria dengan metode AHP

1. Membuat matriks perbandingan berpasangan dari setiap kriteria Membuat mastriks perbandingan berpasangan dengan menggunakan Skala Saaty, dimana kriteria yang digunakan adalah kriteria potensi akademik dan prestasi $(\mathrm{C} 1)$, kemampuan ekonomi (C2), komitmen (C3), urutan kualitas sekolah (C4), representasi sekolah (C5) dan representasi asal daerah (C6). Perhitungan derajat kepentingan yang digunakan dalam perhitungan bobot kriteria adalah $\mathrm{C} 1$ dan $\mathrm{C} 3$ sangan penting dari $\mathrm{C} 5$ dan $\mathrm{C} 6, \mathrm{C} 1$ dan $\mathrm{C} 3$ lebih penting dari $\mathrm{C} 2, \mathrm{C} 1$ dan $\mathrm{C} 3$ lebih penting dari $\mathrm{C} 4$. $\mathrm{C} 2$ sedikit lebih penting dari $\mathrm{C} 4$ dan $\mathrm{C} 2$ lebih penting dari $\mathrm{C} 5$ dan $\mathrm{C} 6$. $\mathrm{C} 4$ sedikit lebih penting dari C5 dan C6, sehingga diperoleh matriks perbandingan berpasangan (X) sebagai berikut:

$$
\begin{aligned}
& C_{1} \quad C_{2} \quad C_{3} \quad C_{4} \quad C_{5} \quad C_{6} \\
& C_{1}\left[\begin{array}{llllll}
1,00 & 1,40 & 1,00 & 2,33 & 7,00 & 7,00
\end{array}\right. \\
& \begin{array}{l|lllllll}
C_{2} & 0,71 & 1,00 & 0,71 & 2,50 & 5,00 & 5,00
\end{array} \\
& \begin{array}{l|lllllll}
X=C_{3} & 1,00 & 1,40 & 1,00 & 2,33 & 7,00 & 7,00
\end{array} \\
& \begin{array}{l|llllll}
C_{4} & 0,43 & 0,60 & 0,43 & 1,00 & 3,00 & 3,00
\end{array} \\
& \begin{array}{l|llllll}
C_{5} & 0,14 & 0,20 & 0,14 & 0,33 & 1,00 & 1,00
\end{array} \\
& C_{6}\left[\begin{array}{llllll}
0,14 & 0,20 & 0,14 & 0,33 & 1,00 & 1,00
\end{array}\right]
\end{aligned}
$$


INTENSIF, Vol.2 No.1 February 2018 ISSN: 2580-409X (Print) / 2549-6824 (Online) http://ojs.unpkediri.ac.id/index.php/intensif

2. Normalisasi matriks berpasangan

Normalisasi matriks dilakukan dengan mambagi setiap nilai $\mathrm{X}$ dengan jumlah setiap kriteria, sehingga menghasilkan matriks normalisasi berpsangan sebagai berikut:

$$
N=\left[\begin{array}{llllll}
0,292 & 0,292 & 0,292 & 0,264 & 0,292 & 0,292 \\
0,208 & 0,208 & 0,208 & 0,283 & 0,208 & 0,208 \\
0,292 & 0,292 & 0,292 & 0,264 & 0,292 & 0,292 \\
0,125 & 0,125 & 0,125 & 0,113 & 0,125 & 0,125 \\
0,042 & 0,042 & 0,042 & 0,038 & 0,042 & 0,042 \\
0,042 & 0,042 & 0,042 & 0,038 & 0,042 & 0,042
\end{array}\right]
$$

3. Menghitung prioritas relatif dari setiap kriteria

Prioritas relatif merupakan bobot yang digunak untuk menghitung matriks $\mathrm{K}$ yang nantinya digunakan untuk mengukur konsistensi bobot kriteria. Perhitungan prioritas relatif dengan membagi jumlah setiap baris kriteria dengan jumlah kriteria yang digunakan. Contoh perhitungan bobot kriteri sebagai berikut:

$P R_{1}=\frac{\sum_{j=1}^{6} N_{1 j}}{n}=\frac{0,292+0,292+0,292+0,264+0,292+0,292}{6}=\frac{1,722}{6}=0,287$

$P R_{2}=\frac{\sum_{j=1}^{6} N_{1 j}}{n}=\frac{0,208+0,208+0,208+0,283+0,208+0,208}{6}=\frac{1,325}{6}=0,221$

Perhitungan ini dilakukan sebanyak kriteria yang digunakan yaitu enam kriteria, sehingga sampai $P R_{6}$.

4. Mengukur konsistensi setiap kriteria

Pada langkah ini, perhitungan dilakukan dengan perkalian bobot kriteria dengan matriks perbandingan berpasangan, sehingga menghasilkan matriks $K$.

$K_{11}=X_{11} \times P R_{1}=1 \times 0,287=0,287$

$K_{12}=X_{12} \times P R_{2}=1,4 \times 0,221=0,309$

Perhitungan ini sampai dengan $K_{6 \times 6}$. sehingga menghasilkan matriks $K$ sebagai berikut:

$$
K=\left[\begin{array}{llllll}
0,287 & 0,309 & 0,287 & 0,287 & 0,287 & 0,287 \\
0,205 & 0,221 & 0,205 & 0,308 & 0,205 & 0,205 \\
0,287 & 0,309 & 0,287 & 0,287 & 0,287 & 0,287 \\
0,123 & 0,132 & 0,123 & 0,123 & 0,123 & 0,123 \\
0,041 & 0,044 & 0,041 & 0,041 & 0,041 & 0,041 \\
0,041 & 0,044 & 0,041 & 0,041 & 0,041 & 0,041
\end{array}\right]
$$


INTENSIF, Vol.2 No.1 February 2018

ISSN: 2580-409X (Print) / 2549-6824 (Online)

http://ojs.unpkediri.ac.id/index.php/intensif

Menjumlahkan nilai matrik $\mathrm{K}$ berdasarkan baris

$\mathrm{BK}_{1}=0,287+0,309+0,287+0,287+0,287+0,287=1,744$

Perhitungan ini sampai pada $B K_{6}$. Hasil perhitungan ini digunakan untuk menghitung $\lambda_{\max }$

$\lambda_{\max }=\frac{\frac{1,744}{0,287}+\frac{1,349}{0,221}+\frac{1,744}{0,287}+\frac{0,748}{0,123}+\frac{0,249}{0,041}+\frac{0,249}{0,041}}{6}=6,082$

5. Menghitung nilai consisteny index (CI)

$$
C I=\frac{\lambda_{\max }-n}{n-1}=\frac{6,082-6}{6-1}=\frac{0,082}{5}=0,0164
$$

6. Menghitung cinsistency ratio (CR)

Menghitung nilai CR dengan kriteria 6 maka Random consistency Index (RI) adalah 1,24

$$
C R=\frac{C I}{R I}=\frac{0,0164}{1,24}=0,013
$$

7. Memeriksa konsistensi penentuan bobot, bila CR kurang dari atau sama dengan 0,1 maka penentuan bobot konsisten, tetapi bila CR lebih besar dari 0,1 maka penentuan bobot kriteria harus diulang kembali. Nilai CR yang dihasilkan 0,013 yang kurang dari 0,1 sehingga dapat dikatakan penentuan bobot kriteria konsisten.

b. Penyeleksian dengan metode VIKOR

Setelah penentuan bobot kriteria dengan dengan metode AHP, selanjutnya dilakukan perengkingan alternatif dengan Metode VIKOR. Langkah pertama dalam perengkingan dengan Metode VIKOR adalah menentukan kriteria- kriteria yang akan dijadikan acuan dalam pengambilan keputusan, yaitu potensi akademik dan prestasi, kemampuan ekonomi, komitmen, urutan kualitas sekolah, representasi sekolah dan representasi asal daerah. Langkah selanjutnya mengikuti prosedur dari metode VIKOR, yaitu:

1. Membuat matriks keputusan dari alternatif dengan ukuran $X_{55 \times 6}$.

$$
X_{55 \times 6}=\left[\begin{array}{cccccc}
23 & 24 & 20 & 5 & 10 & 8 \\
25 & 20 & 20 & 4 & 10 & 8 \\
23 & 20 & 20 & 5 & 10 & 8 \\
21 & 23 & 20 & 5 & 10 & 8 \\
\vdots & \vdots & \vdots & \vdots & \vdots & \vdots \\
1 & 12 & 19 & 5 & 6 & 7
\end{array}\right]
$$


INTENSIF, Vol.2 No.1 February 2018 ISSN: 2580-409X (Print) / 2549-6824 (Online) http://ojs.unpkediri.ac.id/index.php/intensif

2. Menghitung nilai positif dan negatif sebagai solusi ideal dari setiap kriteria

Solusi ideal positif adalah nilai minimum dari masing - masing kriteria dari semua alternatif. Sedangkan nilai ideal negatif adalah nilai maksimum dari masing - masing kriteria dari semua alternatif.

$$
\begin{aligned}
f_{1}^{*} & =\max \left(X_{11}, X_{21}, X_{31}, \cdots, X_{551}\right) \\
& =\max (23,25,23, \cdots, 1) \\
& =25 \\
f_{1}^{-} & =\min \left(X_{11}, X_{21}, X_{31}, \cdots, X_{551}\right) \\
& =\max (23,25,23, \cdots, 1) \\
& =1
\end{aligned}
$$

Pehitungan solusi ideal dari $f_{6}^{+}$dan $f_{6}^{-}$disajikan dalam Tabel 1, berikut:

Tabel 1. NILAI SOLUSI IDEAL

\begin{tabular}{lllllll}
\hline \hline f* & 25 & 24 & 20 & 5 & 10 & 8 \\
\hline f- & 1 & 10 & 19 & 4 & 1 & 7 \\
\hline
\end{tabular}

3. Menghitung matriks normalisasi

Perhitungan matriks normalisasi sebagai berikut:

$$
\begin{aligned}
& N_{11}=\frac{X_{1}^{*}-X_{11}}{X_{1}^{*}-X_{1}^{-}}=\frac{25-23}{25-1}=0,083 \\
& N_{12}=\frac{X_{2}^{*}-X_{12}}{X_{2}^{*}-X_{2}^{-}}=\frac{24-24}{24-10}=0,000
\end{aligned}
$$

dan seterusnya sampai $N_{55}$, sehingga diperoleh matriks normaslisasi $\mathrm{N}$ sebagai berikut:

$$
N_{55 \times 6}=\left[\begin{array}{cccccc}
0,083 & 0,000 & 0,000 & 0,000 & 0,000 & 0,000 \\
0,000 & 0,286 & 0,000 & 0,000 & 1,000 & 0,000 \\
0,042 & 0,286 & 0,000 & 0,000 & 0,000 & 0,000 \\
\vdots & \vdots & \vdots & \vdots & \vdots & \vdots \\
1,000 & 0,857 & 1,000 & 0,000 & 0,444 & 1,000
\end{array}\right]
$$

4. Menghitung bobot normalisasi

Matriks keputusan yang dinormalisasi dikalikan dengan bobot kriteria, sebagai berikut:

$F_{11}=N_{11} \times B K_{1}=0,083 \times 0,287=0,024$

$F_{12}=N_{12} \times B K_{2}=0,000 \times 0,221=0,000$

dan selanjutnya sampai perhitungan $F_{55 \times 6}$. 
INTENSIF, Vol.2 No.1 February 2018

ISSN: 2580-409X (Print) / 2549-6824 (Online)

http://ojs.unpkediri.ac.id/index.php/intensif

$$
F_{55 \times 6}=\left[\begin{array}{cccccc}
0,024 & 0,000 & 0,000 & 0,000 & 0,000 & 0,000 \\
0,000 & 0,063 & 0,000 & 0,123 & 0,000 & 0,000 \\
0,012 & 0,063 & 0,000 & 0,000 & 0,000 & 0,000 \\
\vdots & \vdots & \vdots & \vdots & \vdots & \vdots \\
0,287 & 0,189 & 0,287 & 0,000 & 0,018 & 0,041
\end{array}\right]
$$

5. Menghitung utility measure dari setiap alternantif

Perhitungan utility measure dari setiap alternantif yaitu nilai $S$ dan $R$ :

$$
S_{1}=\sum_{i=1}^{6} F_{1 i}=0,024+0,000+\cdots+0,000=0,024
$$

Perhitungan utility measure $S$ sampai dengan $S_{55}$

$$
\begin{aligned}
R_{1} & =\max \left(F_{11}, F_{12}, \cdots, F_{16}\right) \\
& =\max (0,024,0,000, \cdots, 0,000)=0,024
\end{aligned}
$$

Perhitungan utility measure $R$ sampai dengan $R_{55}$

6. $\quad$ Menghitung indeks VIKOR (Q)

Perhitungan indeks VIKOR (Q), dimana nilai VIKOR yang terpilih menjadi solusi ideal adalah nilai VIKOR terkecil. Perhitungan indeks VIKOR menggunakan rumus berikut:

$$
Q_{1}=\left[v \frac{\left(S_{1}-S^{*}\right)}{\left(S^{-}-S^{*}\right)}\right]+\left[(1-v) \frac{\left(R_{1}-R^{*}\right)}{\left(R^{-}-R^{*}\right)}\right]
$$

Berikut contoh perhitungan indeks VIKOR dengan bobot $(v)$ yang telah diatur 0,5.

$$
\begin{aligned}
S^{-} & =\max \left(S_{1}, S_{2}, S_{3}, \cdots, S_{55}\right) \\
& =\max (0,024,0,186,0,075, \cdots, 0,823)=0,823 \\
S^{*} & =\min \left(S_{1}, S_{2}, S_{3}, \cdots, S_{55}\right) \\
& =\min (0,024,0,186,0,075, \cdots, 0,823)=0,024 \\
R^{-} & =\max \left(R_{1}, R_{2}, R_{3}, \cdots, R_{55}\right) \\
& =\max (0,024,0,123,0,063, \cdots, 0,287)=0,287 \\
R^{*} & =\min \left(R_{1}, R_{2}, R_{3}, \cdots, R_{55}\right) \\
& =\min (0,024,0,123,0,063, \cdots, 0,287)=0,024
\end{aligned}
$$

Sehingga indek VIKOR sebagai berikut:

$$
\begin{aligned}
Q_{1} & =\left[v \frac{\left(S_{1}-S^{*}\right)}{\left(S^{-}-S^{*}\right)}\right]+\left[(1-v) \frac{\left(R_{1}-R^{*}\right)}{\left(R^{-}-R^{*}\right)}\right] \\
& =\left[0,5 \frac{(0,024-0,024)}{(0,823-0,024)}\right]+\left[(1-0,5) \frac{(0,024-0,024)}{(0,287-0,024)}\right] \\
& =0,000
\end{aligned}
$$


INTENSIF, Vol.2 No.1 February 2018 ISSN: 2580-409X (Print) / 2549-6824 (Online) http://ojs.unpkediri.ac.id/index.php/intensif

Perhitungan selanjutnya sampai indeks VIKOR $Q_{55}$.

7. Merangking alternatif dengan mengurutkan mulai dari nilai $Q_{\mathrm{i}}$ terkecil.

Hasil perengkingan calon penerima beasiswa dengan metode VIKOR, dapat disajikan pada Tabel 2.

Tabel 2. Hasil Perangkingan dengan Metode VIKOR

\begin{tabular}{|c|c|c|c|c|c|c|c|c|}
\hline \multirow{2}{*}{$\begin{array}{c}\text { Nama } \\
\text { Mahasiswa }\end{array}$} & \multicolumn{6}{|c|}{ Nilai } & \multirow{2}{*}{$\begin{array}{l}\text { Nilai Indeks } \\
\text { VIKOR (Q) }\end{array}$} & \multirow{2}{*}{ Peringkat } \\
\hline & PAP & $\mathrm{KE}$ & Kom & UKS & $\mathrm{RS}$ & RAD & & \\
\hline M1 & 23 & 24 & 20 & 5 & 10 & 8 & 0,000 & 1 \\
\hline M34 & 22 & 22 & 20 & 5 & 6 & 8 & 0,061 & 2 \\
\hline M8 & 25 & 22 & 20 & 5 & 1 & 8 & 0,063 & 3 \\
\hline M9 & 25 & 22 & 20 & 5 & 1 & 8 & 0,063 & 4 \\
\hline M4 & 21 & 23 & 20 & 5 & 10 & 8 & 0,070 & 5 \\
\hline
\end{tabular}

8. Melakukan solusi kompromi dua solusi, dengan perhitungan sebagai berikut:

Solusi pertama membandingan nilai $D Q$ dengan selisih antara indeks VIKOR pertama dengan kedua atau kondisi Acceptable advantage.

$$
\begin{aligned}
& D Q=\frac{1}{(J-1)}=\frac{1}{(55-1)}=0,023 \\
& Q\left(A^{(2)}\right)-Q\left(A^{(1)}\right)=0,061-0,000=0,061
\end{aligned}
$$

Nilai selisih yang dihasilkan 0,061 lebih besar dari nilai $D Q=0,023$, sehingga kondisi acceptable advantage terpenuhi. Selanjutnya kondisi kompromi dalam proses pengambilan keputusan dilakukan dengan menggunakan bobot $v$ yang berbeda yaitu 0,6 "voting by majority rule" dan $v=0,4$ "with seto". Hasil perengkingan dengan bobot mulai dari 0,$4 ; 0,5$ dan 0,6 menghasilkan perengkingan yang sedikit berbeda pada alternatif, meskipun ada beberapa urutan lain yang mengalami sedikit perubahan dalam perengkingan alternatif. Berdasarkan pembuktian kedua kondisi tersebut dapat diketahui bahwa kedua kondisi tersebut terpenuhi. Sehingga dapat dijadikan sebagai solusi kompromi dari perengkingan calon penerima beasiswa bidikmisi dengan metode VIKOR.

\section{KESIMPULAN DAN SARAN}

Hasil penelitian menunjukkan bahwa penggunaan metode VIKOR dapat membantu proses seleksi dan menentukan penerima beasiswa bidikmisi berdasarkan kriteria yang telah ditetapkan sebelumnya. Pada Metode VIKOR masing - masing bobot yang diberikan menunjukkan hasil 
INTENSIF, Vol.2 No.1 February 2018

ISSN: 2580-409X (Print) / 2549-6824 (Online)

http://ojs.unpkediri.ac.id/index.php/intensif

perangkingan yang sama, sehingga dapat dijadikan sebagai solusi kompromi dalam menangani permasalahan yang multikriteria. Potensi akademik dan prestasi dan komitmen sangat penting dari representasi sekolah dan representasi asal daerah. Potensi akademik dan prestasi dan komitmen lebih penting dari kemampuan ekonomi dan urutan kualitas sekolah. Kemampuan ekonomi sedikit lebih penting dari urutan kualitas sekolah dan kemampuan ekonomi lebih penting representasi sekolah dan representasi asal daerah. Urutan kualitas sekolah sedikit lebih penting dari representasi sekolah dan representasi asal daerah. Saran untuk penelitian ini adalah merancang dan membangun sistem pendukung keputusan penyeleksian calon mahasiswa penerima beasiswa bidikmisi sehingga lebih memudahkan dalam pengambilan keputusan serta menambahkan jumlah kriteria dengan metode VIKOR tersebut di atas.

\section{UCAPAN TERIMAKASIH}

Penulis mengucapkan terima kasih kepada Universitas Terbuka yang telah memberi dukungan financial terhadap penelitian ini, sehingga peneliti dapat menyelesaiakan penelitian ini.

\section{DAFTAR PUSTAKA}

[1] Chiou, H., Tzeng, G., \& Cheng, D. 2005. Evaluating Sustainable Fishing Development Strategis Using Fuzzy MCDM Approach. OMEGA Journal 33(3), 223 - 234.

[2] Turskis, Z., \& Zavadskas, E. 2010. A New Fuzzy Additive Ratio Assesment Method (ARAS-F). Case Study: The Analysis of Fuzzy Multiple Criteria in Order to Select the Logistic Centers Location. TRANSPORT Journal. 25(4), 423 - 432.

[3] Datta, Saurav., Siba Sankar Mahapatra, Sabhyasachi Banerjee, Asish Bandyopadhyay. (2010). "Comparative Study on Application of Utility Concept and VIKOR Method for Vendor Selection". AIMS International Conference on Value-based Management. August 11-13, 2010.

[4] Santawy, Mohamed F. El. (2012). "A VIKOR Method for Solving Personnel Training Selection Problem". International Journal of Computing Science, Vol. 1, No. 2, February, 2012. ISSN (Online): 2164-1374, ISSN (Print): 2164-1366.

[5] Opricovic, S., \& Tzeng, G-H. 2004. Compromise Solution by MCDM Methods: A Comparative Analysis of VIKOR dan TOPSIS. European Journal of Operation Research, 156(2), $445-455$.

[6] Tzeng, G., Huang, J. 2011. Multiple Atribut Decision Making: Methods and Application. Florida: CRC Pres.

[7] Tong, Lee-Ing., Chen, Chi-Chan., Wang, Chung-Ho. (2007). Optimzation of MultiMultiresponse Processes Using the VIKOR Method. Int J Adv Manuf Technol, edisi 31, hal 1049-1057.

[8] Hwang, Ching-Lai, dan Kwangsun Yoon. 1981. Multiple Attribute Decision Making Methods and Application. Verlag Berlin Heidelberg: Springer. 
INTENSIF, Vol.2 No.1 February 2018 ISSN: 2580-409X (Print) / 2549-6824 (Online) http://ojs.unpkediri.ac.id/index.php/intensif

[9] Kahraman, C. 2008. Multi-Criteria Decision Making Methods and Fuzzy Sets. Fuzzy Multi-Criteria Decision Making, Theory and applications with recent Development. Springer.

[10] Mazumdar, A. (2009). Application of Multi-Criteria Decision Making (MCDM) Approached on Teachers' Performance Evaluation and Appraisal. National Institute Of Technology Rourkela 769008, India.

[11] Saaty, T. L. (1990). "An Exposition on the AHP in Reply to the Paper" Remarks on the Analytic Hierarchy Process". Management science 36(3): 259-268. 